\title{
PKM PENDEKATAN TEKNOLOGI MELALUI APLIKASI CERDAS PENOLONG MASYARAKAT UNTUK MENINGKATKAN KEPERCAYAAN MASYARAKAT TERHADAP KEPOLISIAN ATAS TINDAK PIDANA/KEJAHATAN DI KECAMATAN COBLONG BANDUNG
}

\author{
Agus Nursikuwagus ${ }^{1}$, Febilita Wulan Sari ${ }^{2}$, dan Andri Sahata Sitanggang ${ }^{3}$ \\ ${ }^{1}$ Manajemen Informatika, Universitas Komputer Indonesia \\ ${ }^{2}$ Ilmu Hukum, Universitas Komputer Indonesia \\ ${ }^{3}$ Sistem Informasi, Universitas Komputer Indonesia \\ E-mail: andri.sahata@email.unikom.ac.id
}

\begin{abstract}
ABSTRAK. Terjadinya tindak pidana/kejahatan dan kehilangan merupakan salah satu faktor yang selalu meresahkan kepolisian pada khususnya. Tujuan pengabdian ini adalah memberikan pengetahuan kepada masyarakat dan kepolisian mengenai teknologi dalam pelaporan kehilangan, tindak pidana/kejahatan yang ada di Kepolisian Coblong Jawa Barat. Ada 2 metode pendekatan yang dilakukan yaitu tahap pertama menerapkan teknologi pada sisi kepolisian dan tahap kedua menerapkan teknologi berupa aplikasi kepada masyarakat. Dua tahap ini dilakukan dengan cara berdialog kepada masyarakat dan kepolisian, dan mencari solosi atas permasalahan yang terjadi. Maka pengabdian ini akan menghasilkan solusi berupa pembuatan aplikasi tracking dan losing berupa pelaporan berbasis web, aplikasi ini memberikan kemudahan masyarakat dalam melakukan pelaporan kepada kepolisian serta memudahkan kepolisian dalam memberikan status perkembangan atas pelaporan tindak pidana/kejahatan dan kehilangan. Sehingga aplikasi yang sudah diterapkan antara kepolisian dan masyarakat adalah salah satu wujud pengabdian dalam menumbuhkan rasa saling percaya antara masyarakat kepada Kepolisian Coblong Jawa Barat.
\end{abstract}

Kata Kunci: Aplikasi; E-Tracking; E-Losing.

ABSTRACT. The occurrence of crime/crime and loss is one of the factors that always disturbs the police in particular. The purpose of this service is to provide knowledge to the community and the police on technology in reporting a loss, criminal acts/crimes that is in the Coblong West Java Police. There are 2 methods of the approach taken, namely the first stage of applying technology on the police side and the second stage applying technology in the form of application to the community. These two stages are carried out by means of dialogue with the community and the police, and look for solutions to the problems that occur. So this service will produce a solution in the form of making tracking and loosing applications in the form of web-based reporting, this application makes it easy for the public to report to the police and facilitate the police in providing development status for reporting crime / crime and loss. So that the application that has been applied between the police and the community is one form of dedication in fostering mutual trust between the community and the West Java Coblong Police

\section{PENDAHULUAN}

Kepolisian dapat dikatakan sebagai alat negara yang berperan dalam memelihara keamanan dan ketertiban masyarakat, menegakkan hukum serta memberikan perlindungan, pengayoman, dan pelayanan kepada masyarakat dalam rangka terpeliharanya keamanan dalam negeri. Menuru ("UU No.2 Thn 2002 - Kepolisian Negara," n.d.), sudah tentu seharusnya polisi memberikan jaminan keamanan kepada masyarakatnya dalam berbagai aspek kehidupan, dalam hal ini yaitu untuk menangani kasuskasus kejahatan. Di Indonesia banyak sekali kejadian atau kasus dimana masyarakat selalu dikelilingi oleh kejahatan-kejahatan. Hal ini yang merisaukan banyak masyarakat, banyaknya yang terjadi seperti kehilangan barang berharga seperti motor, mobil, uang, emas, suratsurat berharga yaitu SIM, STNK, BPKB dan lainnya menjadi salah satu faktor yang menyebabkan masyarakat bingung untuk melakukan tindakan apa selanjutnya yang harus dilakukan khususnya untuk melakukan pelaporan kehilangan kepada pihak kepolisian.

Ketidaktahuan pengetahuan masyarakat tentang prosedur pelaporan menjadi permasalahan yang berkembang di Indonesia, dan tidak hanya itu ada beberapa kasus yang dianggap oleh masyarakat belum mendapatkan respon/jawaban positif dari pihak kepolisian sehingga menyebabkan masyarakat mengurungkan niatnya untuk membuat laporan, padahal bagi kepolisian hal itu sangat penting untuk polisi dapat menindaklanjuti kasus yang dialami oleh masyarakat. Animo yang berkembang dalam masyarakat seperti itu membuat ketidakpercayaan kepada kepolisian sehingga akan menghambat tugas dari kepolisian. Oleh karena ini maka seharusnya ada mediasi untuk menumbuhkan rasa kepercayaan masyarakat kepada kepolisian mengenai layanan yang diberikan. Menumbuhkan kepercayaan itu hal yang sangat penting untuk menjamin kenyamanan dan keamanan masyarakat.

Makadengan permasalahan tersebut, peran teknologi menjadi salah satu alternatif dalam meningkatkan kualitas pelayanan kepolisian. Dengan adanya fasilitas pelaporan secara online memudahkan masyarakat dalam memahami prosedur pelaporan kehilangan barang berharga baik atas tidak kejahatan ataupun tidak. Fungsi sistem tersebut tidak hanya berfungsi sebagai pelaporan saja, tetapi menjadi pusat media informasi atas usaha kepolisian melakukan penanganan/tidak yang membuahkan hasil atau tidak. Sehingga sistem ini dapat menjadi alat mediasi komunikasi yang baik antara kepolisian dan masyarakat secara global, dan dapat menghilangkan berbagai opini yang menyudutkan kepolisian dalam masyarakat. 
Penerapan system E-Tracking dan E-Losing menjadi berperan sangat penting jika masyarakat dan kepolisan dapat memamfaatkannya dengan maksimal. Dengan adanya penerapan sistem tracking dan losing maka dapat membantu kepolisian sehingga dapat bersinergi dengan masyarakat di dalam menjalankan tugasnya sebagai aparat negara dalam melindungi hak-hak masyakarat.

Maka berdasarkan kajian diatas dapat digambarkan permasalahan yang terjadi dalam masyakarat dan kepolisian Polsek Coblong.

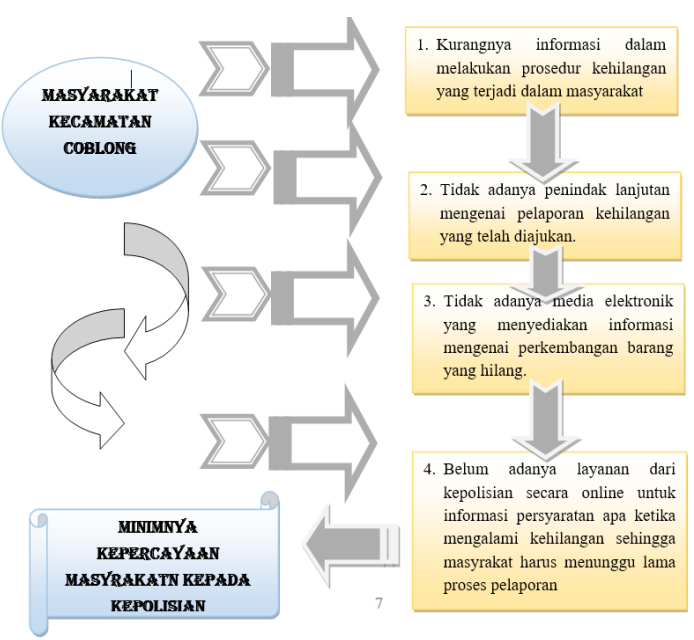

Gambar 1. Permasalahan yang terjadi

Dari penggambaran permasalahan yang terjadi dan beberapa analisis teknologi dari beberapa penelitian yang sudah ada dalam masyarakat, kegiatan pengabdian ini meliputi target dan fungsi pengabdian dapat dijelaskan melalui tabel 1.

\section{Tabel 1 Target dan Fungsi Pengabdian}

\begin{tabular}{|c|c|}
\hline Target Pengabdian & Fungsi dari Pengabdian \\
\hline $\begin{array}{l}\text { 1. Sistem tracking } \\
\text { pelaporan kehilangan } \\
\text { barang berharga } \\
\text { sebagai inputan awal }\end{array}$ & $\begin{aligned} & \text { > } \text { Memberikan fasilitas inputan } \\
& \text { informasi kepada masyarakat } \\
& \text { mengenai informasi pelaporan } \\
& \text { kehilangan } \\
&>\text { Mengecek perkembangan tindak } \\
& \text { lanjut kepolisian atas pelaporan } \\
& \text { yang dibuat oleh masyarakat. } \\
&>\text { Media komunikasi secara langsung } \\
& \text { antara masyarakat coblong dan } \\
& \text { pihak kepolisian. } \\
&>\text { Menjadikan Sistem Menjadi } \\
& \text { Media Sosial sebagai sarana } \\
& \text { informasi mengenai kehilangan } \\
& \text { barang berharga }\end{aligned}$ \\
\hline $\begin{array}{l}\text { 2. Pembuatan System } \\
\text { Losing }\end{array}$ & $\begin{array}{l}\text { Media inputan bagi masyarakat } \\
\text { atas persyaratan yang harus } \\
\text { dilengkapi ketika mengalami } \\
\text { kehilangan barang berharga. } \\
>\text { Menjadi sarana informasi dalam } \\
\text { pengaduan masyakarat kepada } \\
\text { pihak kepolisian. }\end{array}$ \\
\hline $\begin{array}{l}\text { 3. Penyuluhan } \\
\text { penggunaan teknologi } \\
\text { informasi yang } \\
\text { diberikan kepada } \\
\text { masyarakat Coblong } \\
\text { dan Pihak Kepolisian }\end{array}$ & $\begin{array}{l}\text { Memberikan pengetahuan cara } \\
\text { penggunakan system E-Tracking } \\
\text { dan E-Losing kepada masyarakat } \\
\text { dan kepolisian sehingga kepolisan } \\
\text { dapat meningkatkan pelayanan } \\
\text { kepada masyarakat. }\end{array}$ \\
\hline
\end{tabular}

\section{METODE}

Secara garis besar, solusi yang ditawarkan adalah kerjasama antara Tim Pelaksana Pengabdian kepada Masyarakat Unikom dengan Kecamatan Coblong adalah untuk membuatkan sistem E-Tracking dan E-Losing dengan berbagai fungsi-fungsi. Beberapa pendekatan yang digunakan untuk efektifitas hasil pelatihan adalah pada gambar 2.

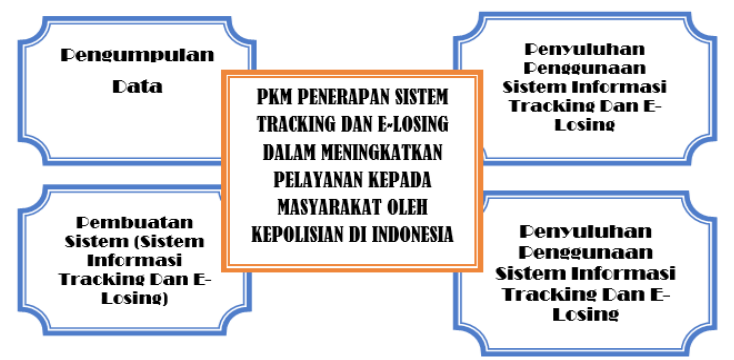

Gambar 2. Metode Pendekatan.

Tahapan ini terdiri dari(Mulyani, R, \& M, 2018):

1. Pengumpulan Data

Dilaksanakan dalam waktu 2 bulan dengan setiap minggunya dengan ketentuan 2 jam, untuk hari ditentukan berdasarkan waktu pihak kepolisian dan bersifat fleksibel. Dilakukan oleh ketua pengabdian untuk wawancara kepada pihak kepolisian, serta anggota kedua sesuai dengan bidang keahlian dalam sistem E-Tracking dan E-Losing.

2. Pembuatan Sistem (Sistem Informasi Tracking Dan E-Losing)

Dilaksanakan Selama 4 bulan terakhir dilakukan dari awal pertama melakukan penelitian. Tugas ini dilakukan oleh anggota pelaksana 1 sebagai anggota analisis sistem dan pembuatan software.

3. Penyuluhan Penggunaan Sistem Informasi E-Tracking Dan E-Losing

Terdiri dari penyuluhan penggunaan Sistem Informasi E-Tracking(Afrizal, Sukmaaji, \& Sutanto, 2013) Dan E-Losing, dari pelatihan tersebut dilakukan selama 2 hari sebelum penyusunan laporan akhir. Pelatihan ini akan diadakan setiap hari jumat dan sabtu dari pukul 08.00-12.00. Kegiatan ini akan dipandu oleh ahli progammer dibidangnya. Kegiatan ini terdiri dari pelatihan penyuluhan kepada kepolisan dan pelatihan kepada masyarakat. Tujuan pelatihan tahapan pertama dilakukan agar kepolisian dapat memamfaatkan fasilitas yang diberikan melalui aplikasi dan dapat meningkatkan layanan kepada masyarakat. Sedangkan untuk pelatihan kepada masyarakat diberikan dengan tujuan adalah agar informasi yang didapatkan oleh masyarakat sebagai pelapor mendapatkan kemudahan dalam mengakses informasi dan memantau perkembangan informasi atas hasil pelaporan.

4. Penyusunan Laporan.

Kegiatan terakhir yang dilakukan setelah proses kegiatan sosialisasi, pelatihan berakhir. Setiap bagian 
sesuai dengan bidang keahliannya masing-masing menyerahkan laporan pertanggungjawaban kepada ketua pelaksana. Dan ketua pelaksana menyelesaikan laporan akhir secara keseluruhan

\section{HASIL DAN PEMBAHASAN}

Perancangan Prosedur E-Tracking yang diusulkan Berikut ini adalah perancangan prosedur yang diusulkan pada Sistem Informasi E-Tracking di Polsek Coblong.

1. Prosedur melakukan registrasi

a. Mengklik menu Registrasi lalu pilih Register.

b. Isi form registrasi sesuai dengan data diri.

c. Klik tombol Simpan maka akan dialihkan secara langsung ke menu List Register.

d. Memeriksa status registrasi di menu List Register.

e. Apabila status sudah berubah menjadi 'diterima', maka pelapor baru bisa melakukan pelaporan kehilangan.

f. SPK melakukan cetak laporan terhadap seluruh data registrasi yang ada.

g. Masuk ke menu Laporan lalu pilih Laporan Registrasi.

h. Isi waktu terhadap registrasi yang masuk kemudian klik Cetak.

2. Prosedur Melakukan Pelaporan Kehilangan (System E-Losing)

a. Pelapor melakukan Login terlebih dahulu.

b. Jika sudah, masuk ke menu Pelaporan ᄀlalu klik Laporkan Kehilangan.

c. Atau pelapor bisa mengikuti langkah-langkah yang tersedia di beranda pada nomor 1 dan klik tulisan Sini.

d. Pelapor mengisi form pelaporan kehilangan secara lengkap dan benar kemudian klik Simpan.

e. Setelah itu pelapor aan otomatis dialihkan ke halaman Daftar Pelaporan Kehilangan.

f. Untuk melihat status kasus yang dilaporkan, lihat pada field Status Pelaporan yang ada di menu Daftar Pelaporan Kehilangan.

g. Pelapor diharuskan untuk mengingat kode pelaporan yang akan digunakan untuk mencetak berita acara.

h. SPK wajib untuk melakukan seleksi terhadap semua pelaporan kehilangan yang masuk.

i. Setelah SPK melakukan login kemudian mengakses menu Penanganan Pelaporan.

j. Pilih salah satu Kode Pelaporan kemudian klik Preview.

k. Setelah memeriksa dengan benar data pelaporan yang masuk, kemudian SPK memilih apakah kasus tersebut akan diproses atau tidak.

1. Jika kasus tersebut diproses maka klik tombol Lakukan Proses Penanganan.

m. Jika kasus tersebut ditolak maka klik tombol Ditolak.

n. Lalu SPK mencetak laporan pelaporan kehilangan yang masuk ke Polsek Coblong.

o. Masuk ke menu Laporan lalu klik Data Pelaporan Kehilangan.

p. Isi tanggal periodik sesuai kebutuan laporan kemudian klik Cetak.

q. Lalu SPK mencetak laporan pelaporan kehilangan yang ditangani.

r. Masuk ke menu Laporan lalu klik Data Pelaporan Kehilangan.

s. Isi tanggal periodik sesuai kebutuan laporan kemudian klik Cetak

t. Prosedur Tindak Lanjut yang diusulkan

a. SPK diharuskan login terlebih dahulu lalu klik menu Tindak Lanjut Pelaporan.

b. Lalu pilih kode polisi yang ada setelah itu klik Preview.

c. Isi keterangan tindaklanjut kasus dan klik salah satu tombol apakah kasus tersebut pidana atau non-pidana.

d. Jika kasus tersebut merupakan kasus pidana maka klik Kasus Pidana.

e. Jika kasus tersebut merupakan kasus nonpidana maka klik Kasus Non-Pidana.

Dengan adanya penelitian yang dilakukan sebelumnya, maka kegiatan pengabdian masyarakat penerapan teknologi dilakukan melalui 2 bagian, yaitu:

1. Pelatihan Aplikasi E-Loosing Berbasis Media Sosial.

Aplikasi ini terdiri dari 3 modul, yaitu modul registrasi, media komunikasi, dan tracking. Masing-masing fungsi disesuaikan berdasarkan metode media sosial yang sudah ada seperti facebook. Maka gambaran aplikasi ini akan sangat mudah dimengerti dan dipahami oleh masyarakat(Nurkamid, Dahlan, Susanto, \& Khotimah, 2010).

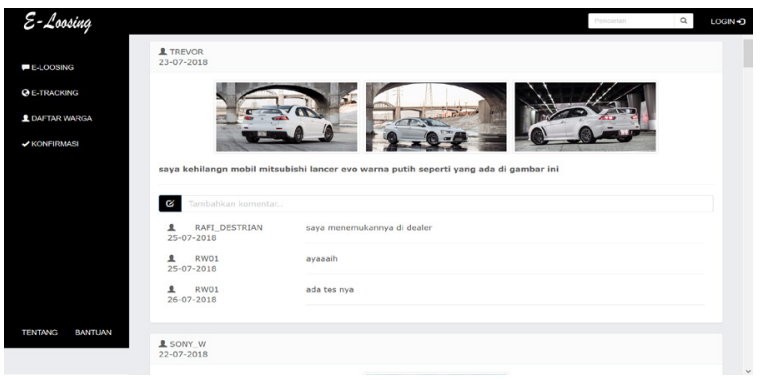

Gambar 3 Aplikasi E-Loosing

2. Pelatihan aplikasi tracking berbasis website

Sebelum melakukan kegiatan pelatihan maka awal kegiatan yang dilakukan adalah:

a. Kegiatan awal PKM

Kegiatan pertama yang dilakukan adalah mengunjungi langsung ke kepolisian Coblong, untuk mengumpulkan data yang berhubungan dengan pelaporan surat tindak pidana/kejahatan, kegiatan ini juga disertai dengan melakukan wawancara dengan beberapa pihak kepolisian mengenai permasalahan 
Terhadap Kepolisian atas Tindak Pidana/Kejahatan di Kecamatan Coblong Bandung

yang terjadi dengan cara berdiskusi/berdialog setiap minggu dalam 1 bulan. Data ini diperlukan terkait dengan membuat solusi atas permasalahan yang terjadi mengenai kasus-kasus yang terjadi di kepolisian, komunikasi antara masyarakat dengan kepolisian mengenai pelaporan yang dibuat.

a. Pembuatan aplikasi tracking berbasis website. Pelatihan ini diberikan kepada kepolisian coblong dengan tujuan meningkatkan pelayanan yang ada dalam internal kepolisian Coblong, aplikasi ini terdiri beberapa fungsi(Supriyono et al., 2016).

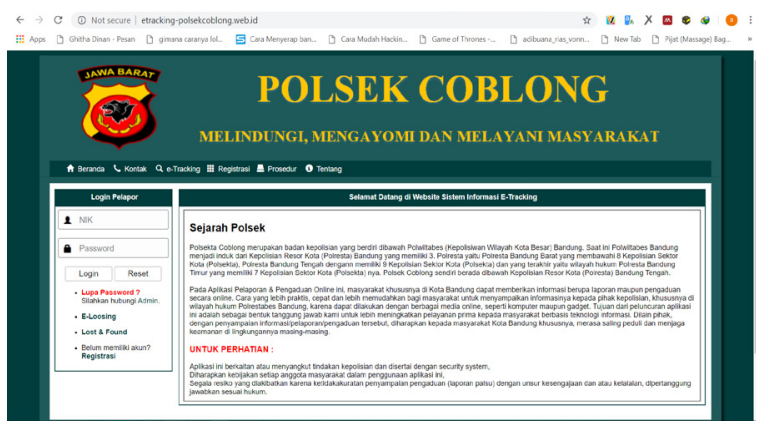

Gambar 4. Aplikasi Tracking

Aplikasi yang dibuat terdiri dari fungsi sebagai berikut:

1. Beranda, dalam menu berisi informasi sejarah dan cara pelaporan kehilangan, tindak pidana/kejahatan yang harus dilakukan oleh masyarkat beserta persyaratannya.

2. Master, fungsi ini mencakup semua data masyarakat yang melakukan pendaftaran pelaporan, data kehilangan, tindak pidana/kejahatan, dan data kepolisian Polsek Coblong.

3. Transaksi, fungsi ini adalah fungsi yang disediakan untuk pihak kepolisian dan masyarakat. Dimana pihak kepolisian diberikan akses untuk menerima pelaporan, mengubah status dan memberikan informasi tindak lanjut sedangkan untuk masyarakat adalah fasilitas untuk membuat laporan dan menerima laporan tindak lanjut pelaporan

4. Cetak laporan, layanan ini memberikan fungsi untuk kepolisian dan masyarakat dalam melakukan pencetakan dokumen sesuai dengan kebutuhan masingmasing.

\section{SIMPULAN}

Kesulitan masyarakat untuk mendapatkan informasi mengenai tindak lanjut dari pelaporan yang sudah dibuat menjadi salah satu alasan masyarakat tidak menindaklanjuti perkembangannya, sedangkan untuk pihak kepolisian terbatasnya media informasi untuk melakukan pelaporan tersebut. Dengan adanya aplikasi ini maka menjadi satu media penghubung antara masyarakat dan kepolisian sehingga menjadi salah satu alternatif dalam menciptakan solusi atas permasalahan yang terjadi diantara dua pihak. Aplikasi ini menghasilkan aplikasi tracking dimana kepolisian dan masyarakat saling bersinergi dalam proses pelaporan yang artinya informasi yang diberikan saling terhubung satu sama lain, sedangkan untuk aplikasi e-loosing merupakan aplikasi berbasis media sosial dimana kepolisian dan masyarakat bisa saling berkomunikasi secara langsung dan realtime. Sehingga komunikasi dapat terjalin antara pihak Kepolisian dan Masyarakat Coblong.

\section{UCAPAN TERIMAKASIH}

Mengucapkan rasa terimakasih yang sebesar-besarnya atas dukungan moril dan dana kepada Direktur Penelitian Dan Pengabdian Masyarakat selama kegiatan pengabdian ini berlangsung, tak lupa kepada Kepala Kepolisian Coblong yang bersedia menjadi objek pengabdian dalam menyelenggarakan kegiatan ini bersama dengan masyarakat Coblong, dan kepada para mahasiswa yang juga ikut terlibat dalam mensukseskan kegiatan pengabdian ini.

\section{DAFTAR PUSTAKA}

Afrizal, Sukmaaji, A., \& Sutanto, T. (2013). Android Personnel Monitoring Location Pada Kepolisian Berbasis Web. Jurnal JSIKA, 3(2), 20-28. Retrieved from https://jurnal.stikom. edu/index.php/jsika/article/view/286

Mulyani, E. L., R, L. R., \& M, A. N. (2018). Smp It Daarussalaam Tasikmalaya, 1(1), 115-123.

Nurkamid, M., Dahlan, M., Susanto, A., \& Khotimah, T. (2010). Pemanfaatan aplikasi jejaring sosial facebook untuk media pembelajaran. Jurnal Sains Dan Teknologi, 3(2), 1-16.

Supriyono, H., Sutopo, A., Nursyahid, H., Kurniawan, B. A., Fahrudin, I. N., Handoko, D., Kurniawan, D. C. (2016). Penerapan Teknologi Web Sekolah Bagi Smp Dan Sma Muhammadiyah Kartasura. Warta LPM, 19(1), 39. https://doi. org/10.23917/warta.v19i1.1983

UU No.2 Thn 2002 - Kepolisian Negara. (n.d.). Retrieved May 25, 2019, from http://hukum. unsrat.ac.id/uu/uu_2_02.htm 